\title{
MUJERES POLÍTICAS Y DESARROLLO RURAL EN ANDALUCÍA
}

\section{POLITICAL WOMEN AND RURAL DEVELOPMENT IN ANDALUSIA}

\author{
Pablo Palenzuela Chamorro ppalenzuela@us.es \\ Universidad de Sevilla. España
}

Cristina Cruces Roldán ccruces@us.es

Universidad de Sevilla. España

\section{RESUMEN}

El artículo analiza la situación que viven las mujeres políticas en los pequeños pueblos de Andalucía, al sur de España, en el marco de las políticas de Desarrollo Rural. Mediante una metodología estadística y fundamentalmente cualitativa, se presentan las estrategias femeninas para alcanzar el empoderamiento (acceso, motivaciones, "estilos femeninos", posiciones, trabajo, socialización de los cargos...) en una arena tradicionalmente masculinizada como la política local, y su compatibilidad con la vida familiar y social.

\section{Palabras clave}

Desarrollo rural, Empoderamiento, Estrategias, Género, Política local.

\begin{abstract}
The article analyses political and familial women strategies in small towns of Andalusia, and the rol of Rural Development Policies in Southern Spain. Through a mainly qualitative and statistical methodology, the authors presents women's ways of enpowerment in local policy (motivations, access, allocation of positions, work, feminine styles, political socialization...), and its compatibility with family and social life.
\end{abstract}

\section{KEYWORDS}

Empowerment, Gender, Local Politics, Rural Development, Strategies. 


\section{INTRODUCCIÓN}

Aun aceptando que los rasgos diferenciales sobre los que se sustentó la clásica polarización rural/urbano (preeminencia del sector primario de la economía, aislamiento relativo y menor prestación de servicios, fuerte control social sobre las conductas, marcada segmentación de espacios y roles por sexos, cierto sentido comunitarista, etc.) están en proceso de disolución, los estudios sobre el medio rural siguen produciéndose desde enfoques disciplinares que, más allá de sus particulares miradas, comparten el reconocimiento de una cierta peculiaridad o especificidad objetiva de las sociedades rurales -aunque la coincidencia en el uso de la denominación no conlleve un amplio consenso sobre su contenido semántico- ${ }^{1}$ y rechazan por tanto su completa homologación con las urbanas.

El concepto de "ruralidad" aparece cuando se constata la objetiva transformación de la llamada "sociedad rural" y se verifica la insuficiencia epistemológica de la polaridad rural/urbano para dar cuenta de la creciente unificación del espacio económico y social debida a la extensión de semejantes relaciones sociales de producción. Es una respuesta, al menos teórica, a estos procesos de cambio social inducidos sobre todo por la crisis del sector agrario, e incorpora las ideas de continuidad del espacio rural/urbano en sus modelos de ordenación del territorio y diversificación económica, la homologación de estilos de vida y, en definitiva, la disolución progresiva de los marcadores arquetípicos atribuidos a la ciudad o al campo. La tesis que subyace es que "el territorio se presenta como un espacio unificado por la relaciones de producción dominantes, es decir, las propias de la sociedad de mercado, pero que las distintas áreas de un espacio así concebido son diferentes, específicas o diversas en la medida en que tienen funciones diferentes dentro de la sociedad global y tienen entidad sólo si se entienden como parte interrelacionada de un todo en el que existen relaciones de dominación" (Palenzuela, Cruces y Jordi 2002:30-31).

No es casualidad que esta propuesta teórica haya sido coetánea a la puesta en marcha de la política europea de Desarrollo Rural, complemento de acción social a la línea estratégica productivista que marca la Política Agraria Común desde principios de los setenta del siglo XX. Desde este momento liminar en la realidad del medio rural en Europa, una buena parte de los especialistas en estudios agrosociales y rurales reorientan su interés hacia el análisis de estas políticas (Moyano 2005). Hasta tal punto esto es así, que podríamos afirmar que los estudios sobre Desarrollo Rural o "Local", como a

\footnotetext{
${ }^{1}$ Normalmente se opta por definiciones operacionales en función del tamaño del asentamiento, la densidad de población, la composición de las rentas domésticas, etc. Este recurso un tanto discrecional hace afirmar a autores como Vera y Rivera (1999:16) que "lo rural no existe, sino que se define". Nuestro estudio delimita los núcleos rurales de Andalucía a los asentamientos poblacionales de menos de 30.000 habitantes, asumiendo que resulta coherente con un límite máximo a partir del cual sus núcleos se incorporarían ya a la categoría de "agrociudad".
} 
veces prefieren llamarse, representan la oportunidad para el resurgimiento de un ámbito de análisis (estudios rurales o estudios de comunidad) que palidecía con la disolución de las llamadas "sociedades campesinas" y, con ellas, la difuminación de los propios campesinos, sujetos tan apreciados como reificados por la tradición socioantropológica del pasado siglo (Wolf 1982; Shanin 1972; Rogers y Svenning 1973; Sevilla Guzmán 1979; Chayanov 1974; Redfield 1973; Palerm 1980).

No obstante, esta reorientación del interés investigador adolece, en nuestra opinión, de un excesivo enfoque institucional/formal y cuantitativista. Se ha pasado de la reificación del sujeto campesino y de su cosmovisión, a una cierta sobrevaloración de las políticas para el medio rural y de las estructuras por ellas creadas. La importancia acordada a "lo estructurante" oculta a menudo "lo estructurado". Las prácticas sociales son vistas como epifenómenos de las estructuras y los agentes sociales aparecen, salvo excepciones (Camarero 2005 y 2007; Sampedro y Camarero 2007; Díaz Méndez 1997 y 2005; Garrido y Moyano 2002; Prados Velasco 2000), como meros receptores y beneficiarios de las políticas de desarrollo rural. Sus estrategias individuales y colectivas, sus prácticas sociales y orientaciones cognitivas apenas encuentran espacio adecuado en la profusión de análisis cuantitativos, institucionales y formales.

El momento de inflexión de esta perspectiva analítica, institucional/formal y cuantitativista, se produce cuando se identifica en las políticas de desarrollo a las mujeres y a los jóvenes como dos colectivos diferenciados que merecen una atención especial por su situación objetivamente desventajosa y, a pesar de ello, por su potencial rol dinamizador de la sociedad rural. De su incorporación activa depende en gran medida el cumplimiento de objetivos estratégicos del Desarrollo Rural, tales como la diversificación productiva y la cultura emprendedora, el relevo generacional en las explotaciones agrarias, el freno al éxodo rural, la disolución de los modelos de conducta excluyentes y patriarcalistas y, en última instancia, la equidad.

En suma, en la disyuntiva rural/urbano y su correlato atraso/modernización están actuando el efecto combinado de la voluntad de esos nuevos sujetos sociales y la aplicación de las iniciativas políticas que, con niveles de eficacia dispares, definen el marco de nuevos modelos de relaciones sociales y aportan los recursos públicos para reducir el diferencial de estándares de bienestar entre el medio rural y el urbano. En el caso andaluz, concretamente, es fundamental el papel desempeñado en la transformación de las estructuras socioeconómicas del medio rural por las mujeres y los jóvenes, en cuanto colectivos lastrados por modelos patriarcalistas y autoritarios, y el impacto positivo de la democratización de la política local y las medidas de discriminación positiva de género en la representación política que se inician con el sistema de cuotas y que sanciona definitivamente la ley orgánica 3/2007 al imponer la paridad en las listas electorales².

\footnotetext{
${ }^{2}$ La disposición adicional $2^{\mathrm{a}}$ de la ley $3 / 2007$ modifica la ley orgánica de régimen electoral general e impone la composición equilibrada de las candidaturas electorales de mujeres y hombres "de forma que en el conjunto de la lista los candidatos de cada uno de los sexos supongan como mínimo el cuarenta por ciento". Esta paridad no se aplica en los municipios de población inferior a 5.000 habitantes.
} 
Precisamente, nuestro artículo ha focalizado su interés en el análisis de las estrategias desarrolladas por el colectivo de mujeres políticas del medio rural andaluz. Un marco territorial que, compartiendo los rasgos diferenciales con el medio urbano que aún justifican el uso de esta denominación distintiva, presenta especificidades en el marco del Estado español como parte de una región históricamente periférica y todavía bastante agrarizada. Pretendemos verificar si la actividad política de estas mujeres consigue desarrollar trayectorias personales y colectivas que permitan superar, en aras de una mayor equidad, los obstáculos y dificultades estructurales que las construcciones sociales de género y las propias restricciones del marco local representan para el desarrollo de sus actividades.

Hemos optado por una metodología que pone en relación datos cuantitativos estadísticos con otros cualitativos que parten del propio discurso de las informantes (emic) ${ }^{3}$. Sin asumir el paradigma del individualismo metodológico que construiría al individuo como sujeto dominante de la acción social y de la toma de decisiones, proponemos una reconciliación que permita buscar los espacios de relación entre las estructuras sociales y las oportunidades reales - de las que participan también las acciones de los otros-y los sujetos específicos, con sus cálculos propios. La contextualización de estos comportamientos individuales se realiza en todo momento desde el marco social de acción, delimitado por una serie de normas que se constituyen a la vez en potencialidades y límites.

Nuestras unidades de análisis principales son las siguientes:

La política institucional, entendida como campo 0 arena de estrategias y decisiones legitimadas desde la representación democrática y la aceptación voluntaria de una función de servicio a la comunidad, centrada en nuestro caso la ocupación de cargos en los ayuntamientos por parte de las mujeres.

El género, como construcción social que asigna roles diferenciados a los individuos de ambos sexos y constituye una categoría estructurante de la identidad social, junto a la identidad étnica y la identidad socio-profesional.

El concepto de estrategia, entendido como el conjunto de procesos de toma de decisiones que, utilizando recursos disponibles, buscan la consecución de objetivos reales y posibles dentro de los condicionantes estructurales, en el seno de procesos sociales más generales.

El empoderamiento, entendido como el proceso que, a partir del reforzamiento de la autoestima, permite a las mujeres decidir autónomamente los ámbitos de su actividad social y participar en ellos en condiciones de igualdad respecto a los hombres.

\footnotetext{
${ }^{3}$ Esta doble orientación metodológica es similar a la aplicada por el Instituto Internacional de Investigaciones y Capacitación de las Naciones Unidas para la Promoción de la Mujer (Instraw) en el informe Participación política de las mujeres en el ámbito local en América Latina, de Alejandra Massolo (2006).
} 


\section{GÉNERO Y ACCIÓN POLÍTICA. El MEdIO RURAL ANDALUZ}

La política se ha definido tradicionalmente como un campo de actividad, una arena de expresión de relaciones, presiones y luchas cuyo parámetro de normalidad se mide en clave masculina -explicación muy cuestionada por el movimiento feminista-, y de la que históricamente la mujer ha sido la gran ausente. Si la dominación patriarcal basada en una división sexual del trabajo ha dado lugar al protagonismo hegemónico de los hombres, dentro de un modelo de división sexual de las tareas que se constata en todas las culturas (Comas 1995:22), la pauta dominante en la arena política es que las mujeres queden apartadas de las tareas de administración del poder comunitario formal, mientras que los hombres tienden a ocupar los papeles de carácter orgánico y naturaleza pública. Demasiado a menudo, el sentido que realmente se otorga al poder es el que puede equipararse con "autoridad", en tanto poder legitimado. La legitimidad hace referencia a una percepción, tanto por parte del que detenta el poder como del que obedece, merced a la cual el primero tiene derecho a tomar decisiones vinculantes o a expresar exigencias, y el segundo tiene la obligación moral de acatarlas. El poder y la autoridad se acumulan en quienes se benefician de los "roles de élite", que a su vez tienden a quedar legitimados por el tiempo.

La legitimidad del poder masculino está desde antiguo tiempo arraigada en la ideología sexual y difícilmente, en un contexto de imperio del poder masculino, las mujeres podrán competir con éxito por los roles de élite en las instituciones sociales dominantes si no participan en ellas. El empoderamiento femenino en las organizaciones partidistas y en el ejercicio del poder ejecutivo supone un desafío al monopolio del poder sustentado en ideologías patriarcalistas excluyentes, en tanto que "empoderamiento significa, en términos políticos, modificar las pautas políticas que coartan la vida personal y colectiva al crear condiciones para eliminar los poderes personales y sociales que oprimen a las mujeres" (Lagarde 2000:27).

En el caso español, el empoderamiento femenino en la política local, en forma de participación activa, es una situación relativamente reciente, en gran medida precipitada por impulsos legislativos, particularmente en la representación política, al asumir el sistema de cuotas de participación. Sobre éstas, no han faltado opiniones a favor y en contra. M. J. Prados, por ejemplo, considera que "la presencia de la mujer en las diversas instancias de representación política responde a la evolución de la sociedad y al mayor protagonismo adquirido por la mujer", y afirma sobre la cuota que "las más de las veces constituye un arma electoral entre partidos políticos y fórmula para intentar atraer el voto femenino" (Prados Velasco 2000:160-162). Para otros -y, sobre todo, "otras"- la aplicación de cuotas es un paso inicial de compensación, indispensable, con lo que "interesa saber si alcanza el objetivo para el cual se proponen como medio: si, en efecto, logran introducir controles dentro de los sistemas de cooptación de tal manera que estos se demasculinicen" (Valcárcel 1997:110).

A pesar de los progresos alcanzados, las mujeres siguen enfrentando más obstáculos y dificultades que los hombres para acceder y mantener posiciones en la toma 
de decisiones políticas. Nos encontramos con "una política de igualdad formal, pero de desigualdad real" (Nordostrom 1990:23-24), lo que evidencia, más si cabe que en otros dominios, las limitaciones reales de las bases democráticas. Como señala J. Astelarra, en la práctica "se establecen otros mecanismos que impiden la incorporación femenina a las actividades políticas y a los puestos de poder. Esta situación es una muestra de que la democracia aún no está construida y que no lo estará mientras varones y mujeres no hayan alcanzado la plena igualdad de posibilidades y las mismas cuotas de participación en todos los niveles" (Astelarra 1986:58).

La expresión "techo de cristal" hace referencia al conjunto de dispositivos discriminatorios, invisibles en principio, que marcan un límite difícil de sobrepasar para la mayoría de las mujeres en las distintas esferas de la vida pública. Esta metáfora, habitual en la literatura feminista, no sólo refiere a la dura frontera para la incorporación de las mujeres a posiciones de responsabilidad y poder, sino también a los instrumentos de segregación vertical por los cuales, a medida que se avanza en la escala jerárquica de una organización, se reduce la presencia de las mujeres respecto a la de los hombres. Estos instrumentos se manifiestan de forma especial en los pequeños núcleos rurales de población donde las culturas de género -como construcción cultural del sexo- se erigen en variable fundamental. La arena política del pequeño marco local establece una posición, si se quiere ambigua, para estas mujeres: de un lado, las limitaciones a sus acciones que establecen las ideologías tradicionales; de otro, una parte de estas mismas ideologías (el sentido comunitario, el familismo) ofrece oportunidades para el encaje personalizado de su papel, e incluso pueden servirles como mecanismos de legitimación, de forma agencial o como causa determinante de su decisión de arraigo en el medio rural ${ }^{4}$.

No es posible negar que se han producido importantes transformaciones en las últimas décadas que impiden una visión simplificadora y estática -fácil de trasladar a un difuso ethos rural- en estos núcleos rurales. En Andalucía, los mayores han crecido en detrimento de los de menor población, se han terciarizado, y ya son intensas las interrelaciones territoriales y funcionales entre localidades. Sin embargo, determinadas estructuras y lógicas económicas, relaciones familiares, valoraciones, pautas de organización social, rituales y ceremoniales, claves simbólicas, ideologías y prácticas cotidianas, circulan en torno a la segmentación de sexos y afectan a las prácticas laborales y de administración del poder público, que se producen según una asignación "sexuada" y "generizada" a hombres y mujeres.

La separación entre espacios domésticos y públicos, la proyección social del trabajo masculino frente a la invisibilización del femenino como simple "ayuda" y la escasa conciliación entre vida familiar y profesional, siguen adquiriendo en estos entornos dimensiones difícilmente compatibles con el discurso de la equidad. La participación de la mujer

\footnotetext{
${ }^{4}$ Para el análisis de los mecanismos psicológicos y los factores que contribuyen al arraigo o desarraigo de las mujeres en el medio rural pueden consultarse los trabajos de Díaz Méndez (2005) y Cruz Souza (2006).
} 
se estructura en cierta medida según la lógica de una organización de tipo familiar, sin contabilización económica de sus tareas. Su administración del poder doméstico está relacionada, más bien, con la mediación emocional y la "caja chica", y combina roles relativos al trabajo reproductivo, productivo y de representación, básicamente orientados en torno a las redes de sociabilidad informal, y mucho menos en organizaciones formalizadas como son los partidos políticos.

Las estadísticas evidencian no obstante que se ha producido un incremento sostenido de la cuota femenina en cargos políticos municipales desde las primeras elecciones democráticas de 1979 hasta hoy. Aunque la igualdad está aún lejos de alcanzarse, en los pequeños núcleos es donde se produjeron precisamente los mayores avances de mujeres candidatas y electas entre las elecciones municipales de 1991 y 1995 y las de 1995 y 1999 , con un notable crecimiento de concejalas, del $17,5 \%$ al $24,9 \%$, en estas últimas $^{5}$. El Informe de la Federación Española de Municipios y Provincias (FEMP) de mayo de 2007, que analiza el impacto de la Ley Orgánica para la Igualdad (LOI) (ley orgánica 3/2007) en la representación de hombres y mujeres en la política local española ${ }^{6}$, concluye asimismo que los municipios andaluces de menos de 5000 habitantes pasaron entre 2003 y 2007 de un 32,08\% de concejalas a un 37,75\%.

Pero la integración de las mujeres en la vida política municipal, una vez superado el primer escalón de conseguir la representación, se ve atravesada por una segregación vertical. Su posición en las candidaturas, así como la posterior ocupación de cargos específicos, sitúan con mayor rigor el concepto de "poder" y su ejercicio, dentro incluso del modelo paritario. El porcentaje de alcaldesas, por ejemplo, pasó en los municipios de menos de 30.000 habitantes del $4,1 \%$ al $8,9 \%$ entre 1995 y 1999 , y en los de menos de 5.000 del $13,1 \%$ al $14,8 \%$ entre 2003 y 2007 .

A su vez, una segregación horizontal de tareas y funciones funciona, de hecho, como una forma de división del trabajo político claramente sexista. No debe considerarse causal la reiterativa colocación de mujeres en áreas programáticas (servicios sociales, cultura, participación ciudadana, etc.), tenidas por "políticas blandas". Responsabilidades relacionadas con el rol familiar de cuidado, atención y prestación de servicios que se extienden, así, desde ámbitos privados a ámbitos públicos, y donde existe mayor compromiso social pero menor poder ejecutivo.

\footnotetext{
${ }^{5}$ En el libro de Palenzuela, Cruces y Jordi (2002) se incluye un detallado anexo en el que se ponían en relación posiciones en las listas con otras variables. Al criterio de "aspiración" y "disposición" a ocupar un cargo público o a su ocupación efectiva se incorporaron la posición que ocupan en series de candidaturas, y el reflejo que su elección tiene en el ejercicio real del poder de decisión y ejecución en los ayuntamientos andaluces. Tras la publicación de la conocida como "ley de igualdad" (LOI), las denominadas "listas cremallera" dan otra dimensión al modelo.

${ }^{6}$ En el conjunto del Estado, de la comparación de los datos de las elecciones de 2003 y 2007 se concluye que el porcentaje de concejalas pasó del $25,7 \%$ al $30,8 \%$ en todos los ayuntamientos. En los de menos de 5.000 habitantes, no afectados por la paridad que impone la LOI, el incremento de concejalas pasó del 22,6\% en 2003 al $27 \%$ en 2007.
} 
Un dato longitudinal expresa con claridad la dependencia que soportan las mujeres respecto a otras exigencias de su vida cotidiana: la eventualidad o alto nivel de rotación que caracteriza su ocupación de cargos públicos, a lo que no es ajeno el funcionamiento interno de las organizaciones de partido. El $77 \%$ de los hombres repitió como concejal en las elecciones de 2007, mientras que sólo lo hizo el 23\% de las concejalas. Asimismo, la escasa permanencia de las mujeres en los cargos políticos representa, en sí misma, un elemento más de discriminación indirecta.

La categoría transversal del género nos permite resignificar en la realidad concreta las medidas estructurales del Desarrollo Rural y nos acerca a la cruda realidad de la doble determinación de las mujeres rurales "en tanto residentes en el medio rural, y en tanto mujeres" (Camarero 1997). Dicho de otra forma, "nos encontramos ante un grupo social, la mujer, y un hábitat, el rural, donde las oportunidades de empleo y las tendencias de cambio cultural y social muestran mayor resistencia. Este es un grupo afectado seriamente por problemas de marginación, discriminación, segregación e invisibilidad" (Bericat y Camarero 1994).

Es por tanto conveniente relativizar el optimismo respecto a la disolución efectiva de los mecanismos que han segmentado, por razones de género, los espacios de participación social y política de las mujeres del medio rural, donde la necesidad de acciones en favor de la igualdad se hace más perentoria. Pero también lo es asimilar el interés que tiene la ocupación femenina de los cargos municipales como objetivo político, por la función que cumplen los representantes locales en los procesos de cambio y en la renovación de la propia sociedad local (Porto y Sampedro 1991:101). Como señala Arrondo, "[l]a participación en el poder local es muy importante, como muestra la experiencia, porque es una parcela de poder sumamente operativa que puede, de alguna manera, revolucionar los cauces de participación social de las mujeres, haciendo que sean reales por la proximidad y la amplia gama de competencias que tiene el ayuntamiento" (1987:264).

Es en estos municipios relativamente pequeños donde las mujeres pueden regenerar el ejercicio del poder político e incorporar un nuevo estilo a la acción política. Jugar un papel doble de "agentes de modernización y cambio" y, por otro lado, una función de "gestión de la vida comunitaria". F. Porto insiste en la trascendencia específica de la participación en la política local, "en la medida en que las responsabilidades políticas van unidas en los gobiernos locales a responsabilidades de gestión que tiene consecuencias inmediatamente visibles para los ciudadanos, concretamente para la economía del municipio" (Porto 1995:26). En la arena política de los pequeños municipios rurales, muchas veces no pesan tanto la militancia y la orientación ideológica de las candidaturas como su inserción previa en redes de cooperación y de actividad cívica que permita acumular personalmente una cuota del "capital social" (Garrido y Moyano 2002), es decir, "la confianza, reciprocidad y reglas de relación cívica en una sociedad, que facilitan la acción coordinada con el fin de lograr objetivos mutuamente deseados" (Bretón 2005:8, citando a T. Carroll). 


\section{Posibilidades y obstáculos de las mujeres políticas. Perfiles y estrategias}

Para el análisis de las estrategias de las mujeres políticas rurales en Andalucía, realizamos una compilación y tratamiento de datos estadísticos, además de un acercamiento cualitativo a 27 mujeres políticas a través de entrevistas semi-directivas ${ }^{7}$. Su discurso emic nos permitió profundizar en la valoración de obstáculos y posibilidades, las trayectorias y experiencias femeninas, y delimitar estrategias particulares para afrontar constricciones y oportunidades, cuestiones sobre las que centramos la exposición: motivaciones y procesos de acceso, asignación de parcelas de poder, relaciones entre familia y trabajo doméstico, socialización de los roles de representación y "estilos femeninos" de hacer política.

\section{Motivaciones y procesos de acceso}

La escasez de casos de mujeres que deciden dedicarse a la "carrera política" como actividad socio-profesional, da medida cierta de la consideración todavía muy extendida de traducir como algo "excepcional" o "raro" el que una mujer sea responsable de funciones de autoridad y mando.

En general, el cargo se contempla entre nuestras informantes como algo eventual, con escasas expectativas de continuidad, y menos aún de proyección supralocal. Sus proyectos suelen ser cortoplacistas o incluso "repentizados", y a menudo emergen como oportunidades sin que hubieran existido diseños estratégicos previos. Entre las diversas motivaciones que declaran como germen de sus decisiones, la mayoría de nuestras informantes defienden el compromiso social y el servicio personal a la comunidad. "La ilusión" por trabajar, por conseguir logros para beneficio colectivo:

"Cuando el pueblo se ilusiona, pues te ilusiona también a ti. Ves que sí, que puedes hacer algo, que hay más gente, que es un equipo que tiene ganas de trabajar y que quieren que tú formes parte de él porque han encontrado que puedes ser válida para lo que ellos quieren. Aunque una en principio no se lo crea, pero te acaba ilusionando, la ilusión se veía en la gente del pueblo y se había conseguido ilusionar a la gente" (Concejala de Cultura, soltera, sin hijos/as).

Ninguna de nuestras entrevistadas contempló la dedicación política como un "trabajo ocasional" o como una ocupación que asegure unos ingresos siquiera sea de forma transitoria. Aunque cabe resaltar que la mayoría desempeñaban su puesto sin retribución y que un porcentaje de ellas estaban desempleadas al incorporarse a la política.

\footnotetext{
${ }^{7}$ Las variables de selección fueron: situación laboral, origen, edad, formación, situación sociofamiliar, provincia, tiempo de dedicación, partido político, nivel de responsabilidad en el cargo y tipo de relación con la organización.
} 
La dedicación al cargo puede llegar a justificarse como una decisión voluntaria en clave de dedicación social, que se confunde a veces con el altruismo y hasta con una afición personal:

"Mi marido 'tolera' que yo haga esto porque no tiene más remedio. Él es muy casero y no le gusta que esté por la noche fuera. Lo consulté con él antes de presentarme y no estaba muy de acuerdo. Ahora lo acepta, pero no lo asume como si fuera un trabajo, sino como 'algo que a ella le gusta, como un hobby'. Esto es dificili negociarlo, es un hueso duro de roer" (Concejala de Asuntos Sociales, Mujer y Trabajo, casada con hijos/as).

Todos los discursos incluyeron, de una u otra forma, lecturas de género: la contribución de la presencia femenina para crear a un nuevo escenario que permita crecer en la igualdad. Distribuir el poder incorporando ese "otro punto de vista" que las mujeres aportan a la política y que eliminaría el carácter monocromo de una actividad casi exclusivamente realizada por hombres. "Femineizar la política" como esquema de acción en el que cada mujer singular es un efectivo que se ensarta en el "nosotros" colectivo de todas las iguales:

"En mi pueblo se planteaba que había muchas cosas que al hombre se le escapan y que necesitan la perspectiva de las mujeres. Yo creo que ellos no pretendían llevar mujeres por llevarlas en las listas, porque ellos son conscientes de que las mujeres ven las cosas desde otro punto de vista, y eso ellos no lo ven aunque se intenten poner en el lugar de una mujer. Ellos querían que se trabajara para todo el pueblo también desde la perspectiva de las mujeres." (Concejala de Cultura, soltera sin hijos/as).

Estas motivaciones personales no son sin embargo independientes de las estrategias diseñadas en el interior de las organizaciones. Los partidos políticos distinguen entre los proyectos formalizados en su seno, algunos de ellos por prescripción legal, y un segundo grupo de estrategias de selección que cuentan con estimaciones más bien personalizadoras a la hora de elegir aspirantes a los cargos. En cuanto a las primeras, las estrategias prescriptivas, la publicación de la conocida como "Ley de Igualdad" y el previo sistema de cuotas que asumieron algunos partidos, se deben contemplar como condicionantes básicos que contrarrestan las prácticas discriminatorias en la vida política por razón de género.

Sin embargo, el sistema paritario es visto por las electas de forma ambivalente, desde su aceptación plena como factor necesario de discriminación positiva (el sistema de cuotas garantizaría las posibilidades de acceso a los cargos públicos a las mujeres, desbordando los límites que impondrían las construcciones sociales de género) hasta su interpretación como síntoma de que la desigualdad persiste, y de que siguen siendo necesarios sistemas normativos para que los puestos de poder no sean monopolizados por varones: 
"Si la cuota no se aplica, los hombres se excusan diciendo que no hay mujeres. Entonces hay que obligar a que se cumpla la cuota, que la pongan, y si no hay mujeres, que las busquen" (Alcaldesa, soltera sin hijos/as).

"Yo lo veo absurdo. Si vales, pues estás dentro de la política. Pero si vales como persona, no como mujer. Creo que, al final, lo de la cuota discrimina [...] Si por el hecho de entrar, va a entrar gente que no es válida lo que se está haciendo es bajar nuestra valoración" (Concejala de Cultura. Casada con hijos/as).

El sistema de cuotas pone en duda, para muchas, las capacidades intrínsecas de las candidatas. Deslegitimador de la valía individual, funcionaría como una "medida tapadera", es decir, de disposición tan fulminante y espectacular como superficial y poco efectiva, que se somete a lo "políticamente correcto" y encubre manipulaciones perversas de la ideología de la equidad. Desde estas posiciones de rechazo, algunas sugieren, antes que nada, que los partidos remuevan sus prácticas patriarcalistas y se esfuercen en la promoción de la militancia femenina y en su formación política. Que renuncien a utilizar la cuota como señuelo para captar el voto femenino, o que diseñen planes más amplios sobre la desigualdad de la mujer en el acceso a la vida política y su posterior desempeño:

"Más vale poquito y arriba que mucho y abajo. Eso de mujeres porque sí, por rellenar... Si esas mujeres reúnen unos requisitos pues si, pero para rellenar una lista con el 25\%, $50 \%$... yo no estoy por eso. Yo creo que la gente los puestos que tengan se los tienen que ganar." (Concejala de Educación y Fiestas Mayores, casada con hijos/as).

"Lo de las 'mujeres floreros'... Yo, a raíz de meterme en esto me he dado cuenta de que el partido, al necesitar mujeres, busca mujeres por un tubo, pero verdaderamente estas mujeres no están motivadas... Yo no quiero que... se nos utilice sino que se nos explique esto cómo va, cómo no va y por qué vamos hacerlo, y una vez que nos lo hayan explicado, hacerlo si quieres hacerlo." (Concejala de la Mujer, casada con hijos/as).

Entre otros elementos particulares que favorecen el acceso al mundo de la política, la valoración individual de cada mujer, su participación previa en organizaciones, su profesión y formación son los más importantes, además de otras capacidades verbalizadas como "femeninas" sobre las que volveremos más adelante. Un nivel de estudios y formación elevado, poco frecuente en los pequeños pueblos, otorga un prestigio personal, un "capital intelectual" que atribuye facultades específicas según la distinción "el que sabe" y "el que no sabe".

El carisma personal de la candidata puede provenir también del ejercicio de una profesión reconocida en el pueblo, o el estar vinculada a acciones de promoción o de asistencia social desinteresadas. La afectación de estas causas estructurales y personales para entrar en política no se produce, sin embargo, de forma independiente, sino según el contexto y las circunstancias particulares. La decisión de lanzarse a la arena política puede derivar de relaciones privadas o familiares, o de la influencia de políticos más 
consagrados -mujeres 0 , más frecuentemente, hombres-, que catapulten iniciativas no muy sólidas de partida con vínculos más personales que ideológicos: compañerismo, amistad, orientación común, profesión e incluso familia. En particular, en aquellos casos en que las organizaciones se han visto obligadas a buscar nombres femeninos para confeccionar las "listas cremallera".

Llama la atención, de hecho, la escasa vinculación que las candidatas mantuvieron con instancias políticas antes de incorporarse por primera vez a sus cargos (19 de las 27 entrevistadas no estaban afiliadas previamente al partido con el que se presentaron), o comprobar que su afiliación es a menudo consecuencia inmediata de la decisión de postularse como candidatas. Muchas de nuestras informantes se declaraban más bien como "simpatizantes" con grandes corrientes ideológicas que como militantes de participación en los partidos políticos, o bien nos confesaban que se adscribieron a unas u otras siglas en función de condicionantes externos a los programas de partido:

"No sabes muy bien por qué te metes en un partido u en otro, a veces pienso que igual podría estar en el PSOE. Pero me encuentro a gusto en un partido o en otro y con la gente que hay" (Concejala de Pedanías, casada con hijos/as).

En general estas mujeres limitan sus expectativas de carrera política al escenario local. Un "techo de cristal" que se explica como ejercicio de responsabilidad voluntaria, como deuda de gratitud con los vecinos. La posibilidad de participar en el ámbito parlamentario autonómico o en la alta política del Estado se verbaliza como una especie de "desatención" para el deber primero. Decisión que, para sus partidos, resulta muchas veces funcional como estrategia de consentimiento y limitación de los recorridos femeninos:

"La verdad es que yo no tengo ambiciones políticas [...] a gran escala. A mí me han pinchado: 'por qué no te presentas para el Parlamento', y yo les he dicho: 'mira, dejadme que yo salga de este laberinto que yo tengo en este ayuntamiento, a ver si soy capaz de ponerlo en pie, y si yo pienso algún día algo de eso ya os lo diré'. Porque yo tampoco me puedo ir a un Parlamento, ni a una Diputación ni nada y [...] semi-abandonar o abandonar a mi pueblo, porque mi pueblo [...] tienes que estar aquí, para sacarlo adelante tienes que estar aqui." (Alcaldesa, casada con hijos/as).

Todo ello contribuye, aún más, a que los cargos municipales se entiendan como periodos coyunturales, como paréntesis en la vida social de las mujeres. El cumplimiento del compromiso asumido tiene, al menos en los inicios de la actividad política, un horizonte predeterminado y la vuelta a la "vida normal" se convierte en el cierre de trayectorias públicas que se sitúan, en la política también, en el marco de la "caja chica":

"No tengo prisa. En la Ejecutiva Provincial me mantengo en la supervivencia, no voy ni para arriba ni para abajo... Yo lo que no voy a estar es haciendo lo que no puedo... porque tengo muchísimo trabajo y no tengo más tiempo como para encima dedicarme 
a vender la moto de lo que estoy haciendo o lo que no estoy haciendo. Digamos que la desmotivación ha llegado ya hasta tal punto que 'paso'. ...o estoy a gusto en mi concejalía, a lo que hago le veo el fruto. Eso es lo bonito de la política local, que lo que haces lo ves, y lo que haces mal también lo ves, y la impotencia muchas veces de no poder atender necesidades que estas viendo. El que está en Madrid no siempre se da cuenta del beneficio o del daño que puede estar haciendo. Es más fructifera la política local." (Teniente de Alcalde, soltera sin hijos/as).

Sería reduccionista, sin embargo, contemplar los modos de acceso femenino a la política como resultado casi exclusivo de las concesiones ofrecidas por una serie de agentes y organizaciones que "proponen" a las mujeres, al margen de sus motivaciones iniciales. Muchas reconocen haber sido "seducidas" por la ocupación de cargos al interior de los partidos o en órganos de representación, pero en general dicen encontrase satisfechas por haber puesto en práctica sus ideas de modo eficiente, y haberse ganado así una parcela de autoridad, de "poder" legitimado por los vecinos. Se reitera en los discursos un afán de autorreconocimiento de las potencialidades propias, y de reconocimiento también por parte de los demás de su capacidad para materializarlas en proyectos concretos.

En este sentido, las mujeres políticas del medio rural perciben su situación como un permanente proceso de evaluación por parte de sus administrados y, sobre todo, por parte de sus compañeros masculinos de corporación. A la vez, asumen una tensión de autoexigencia quizá más alta que la de éstos. Hay que "ganarse el puesto" a base de esfuerzo, de constancia y de dedicación, y "demostrar que se vale", no sólo al acceder a él, sino durante todo el ejercicio político. En definitiva, probar que el electorado no se equivocó, dentro de la línea discursiva de "podemos hacer lo mismo que el hombre" a través del esfuerzo, del conocimiento y el aprendizaje, del trabajo y la experiencia, expresados como verdaderas armas del igualitarismo de género:

"La mujer puede estar en todas las concejalías porque eso todo se aprende, y los miedos no hay quien te los quite." (Concejala de Bienestar Social, casada con hijos/as). "El cambio se da trabajándonoslo. Necesitamos que eso que está en los papeles lo hagamos nuestro, y cuando lo hagamos entonces saldremos a la calle con esa convicción y con esa seguridad en el trabajo, en la vida familiar, en la vida social, con la seguridad de que soy igual, que soy tan válida como otro cualquiera y nadie me puede quitar esto." (Concejala de Cultura, Mujer, Salud y Servicios Sociales, soltera sin hijos/as).

\section{La regla no escrita de asignación de concejalías femineizadas a las mujeres}

Tal como ocurre con la concentración de las iniciativas empresariales femeninas en determinados sectores productivos (artesanías, alimentación, textil, servicios...), también entre las políticas se verifican los efectos de las construcciones sociales de género, al asignárseles aquellas áreas de actividad que se suponen "naturalmente" propias de 
mujeres, a través de las llamadas "concejalías femineizadas" o "concejalías blandas". En palabras de una informante, "es como las asignaturas-maría, ¿no? Pues están las concejalías-maría también". Ese modelo de distribución de las responsabilidades municipales que excluye a las mujeres de Hacienda, Urbanismo, Seguridad Ciudadana, etc., en suma de las concejalías "duras", sólo se rompe en casos muy excepcionales o en supuestos minoritarios de mujeres alcaldesas o tenientes de alcalde.

Evidentemente, la segmentación horizontal de los cargos tiene implicaciones simbólicas y funcionales: se trata de arenas consideradas "menores", que se apartan de ámbitos ejecutivos, lo que tiene traducción inmediata a escala presupuestaria. Pero, frecuentemente, las informantes aceptan las reglas de juego y se acomodan a tareas que estiman honestamente más accesibles para ellas, incluso con la certeza de que otras responsabilidades las colocarían frente a desafíos difícilmente superables, ámbitos de poder que no garantizarían una identificación de "lo político" como "lo personal":

"El hombre, cuando piensa en una mujer piensa en que esa mujer se puede quedar embarazada, que va a tener un niño y que va a estar... primero va a estar unos meses en los que no va a trabajar, en los que no va a desarrollar su trabajo como política 0 como lo que sea. Pero, a la vez, una vez que esa mujer se incorpore no va a tener la misma disponibilidad o, entre comillas, no va a tener la misma disponibilidad que tiene un hombre." (Concejala de Cultura y Turismo, casada sin hijos/as).

Ser delegada de Servicios Sociales, Juventud, Cultura, Festejos, Parques y Jardines, Medio Ambiente o Turismo, suele explicarse no como una estrategia de distribución desigualitaria del poder, sino en relación a ciertos modelos de actuación y con lo que se concibe como el "estilo político femenino". El carácter popular de las tareas propias de estas delegaciones, y los contextos de cercanía personalizada de las mismas, optimizarían una serie de aptitudes "femeninas", como una mayor sensibilidad, capacidad para escuchar y atender los problemas de las personas:

"Para el tema social si es más adecuada la mujer porque la gente se sincera más con una mujer, ya sea hombre como mujer, le cuesta menos trabajo contarle el problema a una mujer." (Alcaldesa, casada con hijos/as).

"Yo creo que las mujeres somos de otra manera, somos más humanitarias, a mí me llega una mujer con un niño chiquitito que yo la conozco, que es del pueblo, que sé que lo está pasando malamente, que está pasando apuros. No sé... me da más lastima que quizás a un hombre. Claro, también hay mujeres muy duras...." (Alcaldesa, soltera sin hijos/as).

Este modelo estereotipado de "circunscripción del medio" es frecuentemente asumido y percibido de forma positiva, como una ventaja. Un reto atractivo para el que las informantes se sienten bien dotadas "como mujeres", no siempre "como políticas" o profesionales. Es por ello que, para la selección de este perfil de mujer política en el seno de 
los grupos municipales, suele importar menos la formación o el perfil de gestora eficaz alejada de sus paisanos, que el que ellas mismas definen como "populista", de política con habilidades en el tratamiento de sus relaciones sociales:

"Al principio tenía temor porque no tenía estudios superiores, y eso me hizo pensar en rechazar el presentarme, pero el alcalde me comentó que el pueblo a quien quiere es a la persona y que yo siempre puedo contar con los técnicos. A medida que pasa el tiempo ese temor va desapareciendo y estoy aprendiendo muchas cosas." (Concejala de Asuntos Sociales, Mujer y Trabajo, casada con hijos/as).

El valor social de estas tareas se mide, entonces, no en clave "política", sino "humana". $Y$ se sustenta en una dedicación paciente, tal vez poco ejecutiva pero extraordinariamente compleja por las connotaciones emocionales y personales que comporta, por la sobrecarga de variedad y cantidad de trabajo. Las concejalas de Cultura nos dicen que la organización de actividades implica dedicar aún más tiempo libre a la actividad política fuera de casa y "a deshoras". Las de Festejos nos reclaman atención al sobreesfuerzo -y casi la frustración- de no estar en la fiesta como una vecina más que disfruta de ella, a la complejidad de la negociación con feriantes y vendedores ambulantes masculinos. Sin embargo, también se avanzan argumentos relativos a la educación diferencial de hombres y mujeres para justificar esta asignación, acercándose a una interpretación externa de la situación. Como también críticas y sospechas acerca de que se distribuyan las concejalías cercanas a los roles domésticos o familiares sistemáticamente entre las mujeres, y manifestaciones de desengaño y humillación:

'Lo que se ha dicho siempre, ¿no? La mujer es la 'ama de casa', la 'madre', la no sé que, la no sé cuantos..., ¿qué concejalías les corresponde por tanto? Pues Servicios Sociales, Juventud... en fin, un poco las que se consideran, no sé por qué motivos, porque no soy capaz de aclarármelo, se considera que están más relacionadas con su forma de ser o su forma de... no sé" (Concejala de Cultura y Turismo, casada sin hijos/as).

"Me siento discriminada como concejala de servicios sociales. Nosotros vamos a ayuntamientos en los que todo el mundo tiene un ordenador, una impresora, un equipamiento... y Servicios Sociales está en el último rincón del Ayuntamiento, sin nada de equipamiento, sin nada de nada... Y generalmente somos mujeres.... dicen: 'ahí viene la niña de Servicios Sociales'” (Concejala de Cultura, casada con hijos/as).

\section{Familia y trabajo doméstico: renuncias, negociaciones y organización}

A juicio de las entrevistadas, la necesidad de simultanear la dedicación al ayuntamiento con la familiar y doméstica, se convierte en el principal obstáculo para su participación en la política local. Pese a los indudables avances en este campo, "la familia" y "la casa" están presentes desde los primeros diseños de la carrera política de una mujer, debido 
al reparto no igualitario de las responsabilidades relativas a la casa, al cuidado de la descendencia y también de los mayores. Cuando existen cargas familiares, el inicio de la actividad en política es más tardío: una cohorte específica de políticas están situadas en la edad de madurez, son mujeres con hijos o hijas mayores y un grado mayor de autonomía personal.

Estas trayectorias vienen atravesadas por los recorridos educativos. Mientras que entre las entrevistadas mayores persiste la consideración de ciertas tareas como un "deber propio de las mujeres", en parejas jóvenes es menos probable encontrar una asimetría total en los repartos de tareas. Las mujeres de menor edad, que no están casadas, o aquéllas que no tienen descendencia, incluso estando mejor dotadas en términos de formación o afianzamiento político en los partidos, dicen por su parte sufrir la contradicción de exigírseles un papel no siempre acorde con expectativas sociales. Para algunas de nuestras informantes, son sus propios partidos los que no siempre asumen el riesgo de "apostar" por estas mujeres para los mejores puestos, porque podrían llegar a provocar extrañeza en el electorado:

"Lo que pasa es lo típico, 'chica joven... esta tiene que ser una niñata'. Eso es asi y te lo digo por experiencia. El año pasado, en la alcaldía había comentarios 'anda que la niñata...', como que es muy chocante para un pueblo, imaginate una persona de edad mediana, eso es impactante. Yo muchas veces lo pienso, yo tenía que haberme casado, tener una familia, quizás eso impone más... Es un handicap." (Teniente de Alcalde, soltera sin hijos/as).

La multiplicación de trabajos se convierte en "triple jornada" para aquellas mujeres políticas que, al no estar liberadas, deben simultanear sus tareas políticas con las profesionales y laborales. Las respuestas estrategias son variadas, comúnmente buscar ayuda fuera de la casa para las tareas domésticas, bien dentro de la familia extensa o por una persona contratada expresamente para ello. Aun así, la negociación en el entorno familiar es una clave indispensable si se quiere facilitar el empoderamiento real de estas mujeres, y algunas de ellas reconocen un contexto de comprensión y colaboración como base de su trabajo.

La sobreactividad, el gran volumen de dedicación en tiempo y esfuerzo que dicen sufrir todas nuestras informantes, se afronta desde tres líneas discursivas:

- La conciencia de que sus problemas tienen que ver con un modelo de construcción social que trasciende la actividad política del marco local. Su situación se evalúa en clave colectiva y no sólo personal; sus problemas son "problemas de género" con independencia de que, en lo individual, cada familia funcione de un modo u otro o que las respuestas se orienten en una u otra dirección:

"Yo percibo que muchas mujeres renuncian a sus cargos, no sólo en política, por sus hijos, incluso profesionales sensibilizadas con el tema de género. Existe el sentimiento 
de culpabilidad, de dejar la casa sola, los niños solos, el qué pensarán de mi. Te condiciona la sociedad, el sistema patriarcal." (Teniente de Alcalde y Concejala de Cultura, soltera sin hijos/as).

- La necesidad de profundizar en una educación para la igualdad, la reversión de un sistema asimétrico en el reparto de las cargas domésticas y familiares. Un logro no siempre alcanzable para su propia generación, con lo que la esperanza se deposita en los hijos/as:

"Mi marido a veces hace la comida, pero cuando termina de hacerla se sienta, aunque yo siga planchando. En este sentido estoy muy descontenta porque las tareas de la casa sigo siendo yo la que las tiene que hacer. Son las mujeres las que tienen que hacer que los hombres cambien, tiene que ser una madre en su casa la que enseñe a los hijos desde chiquitillos, a fregar... a no dárselo todo hecho." (Alcaldesa, casada con hijos/as).

- La activación de modelos eficientes, estrategia inmediata que se verbaliza frecuentemente como "capacidad de organización". Un ajuste funcional para afrontar la pluralidad de frentes abiertos, y un esfuerzo de ordenación mental. Dedicar "cualquier momento" para pensar en organizar una tarea pendiente, que puede no corresponderse con la que en ese instante se esté ejecutando, y que significa estar mentalmente en varios sitios a la vez:

"Es que es imposible desconectar, porque te llevas un montón de cosas, no sólo problemas, cosas que tienes que hacer y que arreglar, gente que te viene diciendo 'que mi calle, que esto, que lo otro...' Entonces cuando llegas a tu casa y te sientas diez minutos te pones a asentar las ideas, y dices, 'bueno, ahora ¿qué es lo que tengo que hacer?, pues tengo que hacer mañana esto y esto, y tengo que decirle a aquél esto otro... entonces no desconectas, desconectas cuando duermes, si es que duermes." (Alcaldesa, soltera sin hijos/as).

"Yo cuando me reúno con los alcaldes los veo más relajados, mientras que yo estoy pensando en que todavía no tengo nada para comer al día siguiente." (Alcaldesa, casada con hijos/as).

La compatibilización de tiempos y esfuerzos y la existencia de un único tiempo intercambiable de "trabajo" y "no trabajo" genera sentimientos de culpa y abandono, de llevar "más trabajos de la cuenta", ninguno de ellos con la perfección deseada, de desplegar un continuo esfuerzo de elección. Y, desde luego, comporta un coste importante en cuanto a la disposición de tiempo libre, que se dedica sistemáticamente a cumplimentar las tareas pendientes:

"Lo que no haces por la mañana lo tienes que hacer por la tarde, y a mi niña intento dedicarle el máximo de tiempo posible y aprovechar los fines de semana, pero la falta 
tiene que quedar en algún lado, y siempre se queda en las tareas de casa, porque tienes que cumplir con tu horario. En mi tiempo libre, el poco que me queda, me dedico a pasear con mi hija y al cuidado de mi hija. Antes me gustaba pintar y leer pero eso pasó a la historia, hasta que la niña no sea mayor." (Teniente de Alcalde y Concejala de Mujer, casada con hijos/as).

La falta de tiempo tiene también sus efectos en el mundo social de estas mujeres, que han de atender a las relaciones personales, pero también políticas y de partido. Las amistades se resienten, según dicen, y sobre ellas -como sobre la familia- se vuelcan el cansancio o los enfados que no se han podido saldar en el tiempo de trabajo político. En cualquier caso, no parece desprenderse de los discursos un excesivo fatalismo, sino más bien la expectativa de que sean los otros los que se amolden a los nuevos requerimientos:

"Es necesario salir del ambiente. Yo a veces me crispo y lo pago con la gente que tengo a mi alrededor. No lo pago... me enfado excesivamente, les doy una de cal y otra de arena, pero bueno... ellos (mis amigos) me entienden, y ya casi ya no me hacen caso." ( $2^{a}$ Teniente de alcalde, Concejala de Cultura, Festejos, Deporte y Turismo, soltera sin hijos/as).

El abandono de la carrera política es la única salida en caso de no poder tener la casa atendida 0 no mantener unas relaciones de afectividad y dedicación hacia los hijos/ as el sentimiento de culpa por el "abandono de la familia", al dedicarle menos tiempo y atención, en un componente identitario básicamente emocional, y al cual no quieren renunciar. Es este el momento en el que algunas de nuestras entrevistadas ponderan que ha llegado la hora de "pensarse el cargo".

\section{La representación política, un rol socializado}

Como ya se ha dicho, el mundo rural exige hacer "otro" tipo de política, más personalizada, en la que los vecinos votantes y no votantes conviven con sus representantes, y donde la cercanía y el diálogo se hacen inevitables. La concejala o la alcaldesa no es una mera representante administrativa al margen de su comunidad, sino que es parte de ella: su familia puede tener una tienda, los vecinos la han visto crecer y han crecido junto a ella, conocen a la persona en facetas ajenas al cargo.

La incorporación a redes comunitarias y familistas es un factor que se demuestra inserto "en positivo" en los procesos de empoderamiento femenino (Díaz 2005), pero en la mayoría de los casos se verbaliza por nuestras informantes como una constricción: los paseos por la calle se convierten en improvisadas reuniones y consultas de trabajo, y la intimidad y la publicidad, espacios tradicionalmente diáfanos para las vivencias de las mujeres, pierden sus fronteras. La condición de éstas es accesible, pública, siempre disponible.

A ello se añaden los ritmos propios de los partidos, que obligan a una presencia física fuera de los horarios habituales de trabajo. Reuniones 0 asambleas tienen lugar a 
deshoras, y obstaculizan la disposición de tiempos propios. La reclamación de tiempos acordes con los calendarios femeninos es una constante:

"Suelen pararme por la calle a todas horas y eso me molesta mucho, porque deberían de saber distinguir entre el horario de trabajo y el que no es de trabajo, pero en los pueblos nos conocemos todos y se aprovechan de eso... También es una ventaja porque estas muy cerca del ciudadano." (2a Teniente de Alcalde, Concejala de Educación y Personal, casada con hijos/as).

"He perdido la intimidad, a cualquier hora me llaman, van a mi casa, me paran por todos sitios." (Alcaldesa, casada con hijos/as).

En este marco comunitario, además, las opiniones y juicios de la gente cercana, sus inquietudes y sus problemas, se convierten en factor principal a la hora de orientar la gestión cotidiana. Muchas concejalas o alcaldesas mencionan la problemática del control social, los riesgos de murmuraciones, rumores o etiquetas locales, e incluso el "plus" de desprestigio potencial que conlleva su actividad pública:

"Tienes que ir con mucha picardía, mucho cuidado con lo que hablas, con lo que dices, en qué ambiente te mueves porque estás respondiendo a un pueblo y a un municipio que está mirando lo que haces y lo que dices, tienes más limitaciones porque cualquier cosa te la pueden echar en cara." (Concejala de la Mujer, casada con hijos/as).

Sanciones que no son exclusivamente individuales, sino que tienen una reverberación en clave familiar y social que las mujeres viven de un modo traumático en casos de conflicto. Muchas entrevistadas declaraban sentirse preparadas para superar comentarios negativos o cotilleos hacia su persona, pero no así la afectación a sus familias. La crítica hacia la mujer política puede afectar desde al "honor" del marido hasta el "buen nombre" de los padres, de modo que la carga social adscrita ante las responsabilidades adquiridas comporta una indiscutible dimensión de género. Aquí se pone de manifiesto la doble dirección del control social: de una parte, los riesgos del entrecruzamiento de papeles y la localización de estas mujeres en dinámicas y redes familiares, vecinales o de amistad; de otra, las potencialidades de resistencia de que hacen gala estas mujeres, a través del apoyo de la familia y de la propia actitud de los vecinos, que conocen su vida y su trayectoria:

"Mis padres al principio no entendían por qué me tenía que meter en estos líos, lo pasaban mal cuando había criticas sobre mí que no me favorecian, se preocupaban en el sentido de que yo me equivocase y tuviera problemas y me repercutiera en otros ámbitos." (Alcaldesa, casada con hijos/as).

"A mi marido le duelen los comentarios en contra mía más que a mí, y eso me preocupa." (Alcaldesa, casada con hijos/as).

"A mi marido han llegado a decirle: 'yo nunca dejaría que mi mujer esté donde está la tuya." (Concejala de Asuntos Sociales, casada con hijos/as). 
Las respuestas individuales suelen estar en la línea de la autoexigencia y del desafío personal para demostrar a los demás (especialmente a los hombres) la capacidad que supuestamente aportan las mujeres a cualquier actividad. Se suelen desarrollar entonces una serie de valoraciones positivas relativas al sobreesfuerzo, la entrega o el sacrificio desmedido, sentimientos de hiperresponsabilidad con que estas mujeres afrontan el mundo de la política:

"Quizás por ser menos y querer tener un lugar le echemos más coraje, más tiempo, tenemos más sensibilidad para casi todo y si le ponemos sensibilidad a la cuestión politica pues nos volcamos totalmente, nos sacrificamos realmente" (2 $2^{\mathrm{a}}$ Teniente de Alcalde, Concejala de Cultura, soltera, sin hijos/as).

\section{El "estilo femenino" de hacer política}

Ello nos conduce al debate sobre la existencia o no de unos rasgos específicos del ejercicio femenino del poder, que en general no se considera de la misma naturaleza que el masculino, ni connota de la misma forma que éste. Valcárcel (1997) describe el "poder femenino" como un poder genéricamente no significativo y sujeto a transacciones externas, además de inestable, dadas las condiciones especiales en las que se detenta. Barberá Heredia, por su parte, sintetiza la especificidad del poder femenino en las organizaciones en dos características básicas: una relación basada en la colaboración interactiva, poco jerarquizada, y la utilización de la intuición y la empatía como una forma adecuada de resolución de problemas (2001).

La cuestión que subyace es si, más allá de los condicionantes concretos del ámbito local, existen o no modos "masculinos" y "femeninos" de hacer política. Las respuestas ofrecidas por las mujeres políticas del medio rural andaluz caen frecuentemente en una contradicción: en positivo, resaltan una serie de aptitudes o cualidades diferenciales entre hombres y mujeres a la hora de administrar el poder; a la vez, abogan por una desnaturalización del género y niegan el poder normativo del estereotipo femenino, con la certeza de que, si existen, las diferencias en los modos de hacer política se dan, por encima de todo, a escala personal. No existiría en este caso "un estilo" femenino de hacer política, sino "muchos estilos". La profesión, el estado civil y la edad se plantean como criterios paralelos de identificación que superan las simplificadoras plantillas "hombres vs. mujeres":

"Yo ya he dejado de dividir el mundo entre hombres y mujeres. Yo pienso que la cosa no va por ahí. Yo el mundo lo divido en personas, personas que valen para una cosa y personas que valen para otra... no creo que haya un estilo de hacer política de los hombres ni de las mujeres." (Alcaldesa, soltera sin hijos/as).

"Yo lo haré pues como soy, soy una mujer de 31 años, madre con una hija de pequeña, diplomada en Trabajo Social y está claro que no lo haré igual que mi compañero que tiene treinta años que es soltero y que ha estudiado aparejador, el tendrá una visión diferente de los problemas sociales a como la tengo yo" (Teniente de Alcalde, casada con hijos/as). 
Sobrevuela no obstante la convención de que ciertos rasgos femeninos impregnan la forma de actuar y de pensar en la política. La tenacidad y la capacidad de organización de tareas, tiempos y equipos centran parte de los testimonios. "Fortaleza" $y$ "resistencia" son algunas etiquetas que las políticas aplican a su manera de trabajar, bajo la afirmación de que "las mujeres tienen mayor capacidad de sufrimiento". A las duras condiciones en que se ven impelidas a detentar el cargo se une la superación previa de barreras para alcanzarlo. Frecuentemente, se recurre a la etiqueta de la "supermujer", capaz de traspasar cualquier obstáculo por difícil y costoso que parezca. Un ideal que se convierte a la vez en referente, barrera y frustración:

“Las mujeres son muy tozudas, dicen 'esto hay que hacerlo' y nos dejamos la piel para llegar a conseguirlo, o sea que tenemos que demostrar lo que ellos tienen demostrado, trabajamos más pero nos van a exigir más y lo sabemos de antemano" (Alcaldesa, casada con hijos/as).

"He trabajado con hombres y mujeres mucho tiempo y las mujeres son mucho más luchadoras, porque no hemos tenido la vía y el camino abierto. Entonces para que estemos ahí tenemos que luchar" (Concejala de Hacienda, Educación y Personal, divorciada con hijos/as).

La capacidad de resistencia femenina se acompaña sin embargo de una serie de valores como la ductilidad, la predisposición a la negociación y al consenso, la mayor sensibilidad, la mayor sensibilidad social etc., que se suelen naturalizar por parte de las mismas mujeres mediante comparaciones continuas con el frío y competitivo mundo de la política masculina, con la hostilidad que lo atraviesa. Muchas informantes nos hablan del coste emocional inherente a la preocupación por las actuaciones públicas que desempeñan -muchas de ellas en áreas que afectan inmediatamente a la vida de los vecinos-, de la responsabilidad y las repercusiones personales de sus tareas. Se ven a sí mismas como mujeres siempre "al pie del cañón" que aportarían un "instinto" especial, una comprensión y una "humanidad" aplicada a las relaciones sociales, estereotipándose así también ellas:

"Somos más duras que los hombres, somos más sufridoras y todo eso que dicen. Tenemos más sentido de la responsabilidad, tenemos más sentimiento... somos más sensibles en cuanto a problemas y demás. Yo pienso que sí, que somos más duras que el hombre, más sufridoras." (Concejala de Cultura y Turismo, casada sin hijos/as).

"Yo creo que las mujeres aportamos como, no sé cómo definirlo pero... más humanidad, es que no sé, no sé como decirlo pero es distinto la política del hombre a la de la mujer, quizás los hombres son más agresivos." (1 ${ }^{a}$ Teniente de Alcalde, casada con hijos/as).

Según verbalizan nuestras informantes, otras de las "armas alternativas" que aportarían a un modo de funcionamiento masculinizado, cuyos cánones dicen no compartir, son la 
capacidad de diálogo, la socialización del trabajo, la delicadeza en el trato personal, el autocontrol. Se suele apelar a la fuerza del verbo y de la razón de las mujeres frente a la acción, al sosiego frente a la prepotencia y al estilo agresivo de los varones:

"Pienso que la mujer es mucho más dialogante a la hora de negociar, hablar, saber llegar a la gente... pierde menos los papeles." (Alcaldesa, soltera sin hijos/as).

En sus tareas, nuestras políticas conceden una gran importancia al campo de "lo relacional": la facilidad en un trato directo y menos rudo, la medida de las "anónimas relaciones políticas" a escala humana, son capacidades que se atribuyen a sí mismas como un ejercicio de la política alejado de los entresijos exclusivamente burocráticos. Distinguen, por ejemplo, entre "gobernar" y "mandar", apostando por un estilo distintivo que califican como "afable" y "cordial". Si la identificación dominante es la de "Io formal" con "lo verdaderamente político", y de "lo personalizado" y "social" como "lo no político", la consecuencia, en términos de desigualdad de género y hegemonía masculina, es evidente. Muchas de nuestras informantes, no por casualidad, se describen a sí mismas como "no políticas":

"Desde que hemos llegado al ayuntamiento no hemos sido politicas, politicas sino personas que quieren hacer algo por su pueblo lo mejor que puedan." (Alcaldesa, casada con hijos/as).

"No me gusta dedicarme a la política. Como yo no soy política, cuando voy a los plenos ni siquiera sé los trámites burocráticos que hay que presentar, yo los presento pero me asesora el técnico, o cualquiera, porque no me gusta." (Concejala de Cultura, casada con hijos/as).

Maximizar y priorizar relaciones en clave humana significa también una apuesta por el compañerismo y la solidaridad, por negociar y colaborar, que estas políticas verbalizan como ajenos a la característica competitividad masculina de la lucha política por el poder. Los testimonios en los que se habla del equipo de gobierno como un "grupo" de personas que adopta las decisiones colectivamente son abundantes. Si contamos con las escasas aspiraciones de muchas, que reconocen su paso por la política como algo "transitorio", "de compromiso", y que no planifican carreras personales profesionales, no extrañarán entonces las estrategias de delegación en detrimento de las de concentración del poder:

"Aquí, por ejemplo, el anterior alcalde no había delegado en ningún concejal. Yo, por el contrario soy muy consciente de que no lo puedo hacer yo todo sola y delego, pero de forma que cada concejal en su parcela tenga poder. Esto a la gente del pueblo en principio le chocaba, pero ya lo ven como algo normal y no buscan a la alcaldesa para todo sino al concejal correspondiente." (Alcaldesa, casada con hijos/as). 
Parece que se hace extensible a todos los discursos, como premisa "de género", la referencia a la capacidad organizativa a la que hemos aludido, tanto en el manejo del tiempo como en el de los recursos, y que descansa en una extensión del modelo de la vida doméstica:

"Las mujeres estamos más acostumbradas a llevar más cosas en la cabeza, eso si es verdad. El hombre lleva cinco cosas y 'ay madre mía el agobio...' y la mujer lleva diez y se queda una tan campante. Una alcaldesa por estar acostumbrada a sus vivencias, una alcaldesa casada... cuando tiene tantas cosas sabe mejor cómo planificar. No es que la mujer esté más capacitada para planificar y para todo, sino que en esta vida le han dado... lo mismo que al hombre le han dado unas cosas, a ellas le han dado otras. A ti te vamos a dar a estos hijos sin estar remunerada, la carga familiar, la economía... la mujer ha tenido que estar capacitada. No sé, que se las ha tenido que arreglar y ya está." (Concejala de Hacienda, Educación y Personal, divorciada con hijos/as).

En parte, ese criterio de organización tiene que ver con la eficiencia: muchas informantes han hablado de aprovechar el tiempo o ir al grano como expresiones que manifiestan un interés por la planificación eficaz. La evitación de hábitos como el de "la cervecita después del trabajo", motivo de reunión masculinizado, se justifica por el desprecio ante su insolvencia o por la carga simbólica que tiene en estos núcleos pequeños:

"A las doce cuando terminan se van a tomar una copita. Yo a las doce me voy a mi casa. Hombre, un día si hay que tomarse una copita porque el pleno ha salido muy bien, muy bien pues me voy un día, pero por sistema yo el día del pleno no llego a las tres de la mañana a mi casa, lo que en otros compañeros sí es lo normal, para mí no es lo normal. Es que ya he salido a las seis de mi casa y tengo ganas de llegar, y sé que me están esperando. Procuro llevarlo bien porque procuro que en mi casa se note lo menos posible mi actividad política, y lo compagino bastante bien" (Concejala de Fomento, Formación y Empleo, casada con hijos/as).

En relación con la organización de los recursos, y ante la escasez de medios de muchas de las concejalías que les son atribuidas, una estrategia en la que coincidieron muchas de las entrevistadas pasa por aplicar al trabajo público las supuestas habilidades características en el manejo de las "pequeñas economías", como algo procedente de un cuerpo de aptitudes y experiencias vividas en el ámbito doméstico y familiar.

Finalmente, las mujeres políticas del medio rural se ven a sí mismas diferentes de sus émulos masculinos en razón de la sinceridad y honestidad con la que acometen sus tareas. Un mayor sentimiento de responsabilidad implica también saber reconocer los errores cuando se cometen. La integridad a la hora de tomar posiciones en lo político, lo que algunas definen como la falta de maldad, se ven virtudes propias del género femenino: 
"Somos más responsables, somos más claras, es decir... yo es que soy muy clara.... te responde mejor las mujeres que un hombre. Si por ejemplo alguien ha cometido un fallo o lo que sea lo sabe admitir mejor una mujer que un hombre. Cuando hay un problema se encara mejor por una mujer que por un hombre, si hay que decirse lo que sea a nivel de subordinados también son más claras pues te has equivocado aquí y lo reconoces. Yo reconozco que me he equivocado, no me cuesta trabajo reconocerlo en absoluto." ( $1^{\mathrm{a}}$ Teniente de Alcalde, casada con hijos/as).

Los modos de ascenso en la jerarquía de cargos de los partidos, marcados por la competencia y la hegemonía masculina, son a menudo objeto de rechazo. Frente a la ambición como "hoja de ruta" masculina, nuestras mujeres se ven a sí mismas continuamente requeridas para demostrar lo que valen:

"Sólo por el hecho de que tú seas mujer te van a examinar para ver si eres válida o no válida, mientras el político entra del tirón, el hombre entra del tirón, parece que lo tiene todo resuelto, no tiene que demostrar nada, la mujer tiene que demostrar más, si vale o no vales tienes que demostrarlo. Hay un montón de políticos que son una birria, y no tienen que demostrarlo... la mujer lo primero que tiene hacer es demostrar si vale o si es sólo una carita bonita." (Concejala de Cultura y Turismo, casada con hijos/as).

Con estos testimonios, puede extrañar un dato: la mayoría de informantes se posiciona muy lejos de los discursos radicales de las corrientes feministas. Es infrecuente, de hecho, que militen en asociaciones locales de mujeres de esta naturaleza. El estilo dominante es aconflictual, moderado y generalista. Identifica como "feminismo real" la práctica cotidiana, paso a paso, de tantas mujeres anónimas que no presentan resistencias directas y confrontadas pero que "construyen igualdad":

"Creo que las mujeres reconocen lo positivo del hombre. El problema está en que los hombres no reconocen lo positivo de la mujer. Nosotras no queremos que no estén ellos; al contrario queremos que estén" (ídem).

"Luchar con las armas de los hombres" se considera una estrategia radical, que nuestras mujeres dicen adoptar sólo en situaciones extremas y cuando ya se han agotado otros recursos. Algunas hablan de una agresividad latente, reservada para momentos calculados. La "masculinización del poder" es la estrategia última, poco aceptada y compartida, pero también practicada:

"Yo creo que la mujer se debe de colocar en su sitio, no tiene por qué ser agresiva. Pero a mí me gusta que sea como una manera de 'pararles los pies' a los hombres, y 'cantarles las cuarenta' en el momento que haya que cantárselas, es decir, como persona 
ser respetuosa en su momento y cuando haya que ser agresiva, serlo." (Concejala de la Mujer, casada con hijos/as).

"Lo que pasa que cuando llegamos cogemos el referente del hombre. El referente masculino es como una perversión, el referente femenino es como una invisibilidad, es que no lo vemos o no queremos verlo. $Y$ otras veces es que no te dejan actuar de otra manera: esto son las reglas del juego y esto es lo que hay... encima de que nos cuesta llegar, si cuando llegas dicen pues esto ya no." (Teniente de Alcalde y Concejala de Cultura, soltera sin hijos/as).

No faltan testimonios que hablan de mujeres que acceden a sus puestos de poder y se olvidan de los esfuerzos que tuvieron que emplear y los obstáculos que tuvieron que sortear para llegar donde se encuentran; mujeres que prescinden de la solidaridad por razón de género y que se apegan al poder, olvidando su papel como representación de otras muchas. Esta conducta las convertiría, señalan, en una especie de "agentes androcéntricos", poco ejemplares para sus iguales. Las rencillas femeninas, las envidias, la rivalidad y la vanidad personal aparecen también en nuestros testimonios:

"Una vez que estamos en la política metidas, la que ya está arriba no se da cuenta de que estuvo abajo, y es egoísta. Yo sé de mujeres que se sientan en sus sillitas y el asiento es para ellas, y esa no cede el puesto ni a tiros... Ahí la mujer ya se pone en competencia con ella misma." (Concejala de la Mujer, casada con hijos/as).

"En política somos más envidiosas las mujeres que los hombres, entre las mujeres, yo tengo mucha confianza con algunas y con otras, no cuentas todas las cosas, si tú consigues una cosa y ves que la otra le gustaría menos no se la cuentas... las mujeres somos más rivales" (Alcaldesa, soltera sin hijos/as).

Con todo lo dicho, hay que resaltar que las mujeres políticas de nuestra investigación mueven sus percepciones entre difusas líneas discursivas que, a veces, llegan a contradecirse. El enmascaramiento, incluso los silencios a los que hemos asistido en nuestras entrevistas, son algunos signos de la indefinición con que ellas mismas afrontan sus posiciones en la arena política. Son conscientes de ser una minoría, pero tienen claro que su situación es la prueba de que la sociedad está cambiando. Perciben que son pioneras al inicio de un camino hacia lejanos horizontes, pero aceptan la transitoriedad de su función y se desenvuelven de modo finalista en sus tareas cotidianas.

La pregunta que emerge es si, con el tiempo, estas mujeres que sirven a la comunidad mantendrán sus posiciones inamovibles, se quedarán encasilladas en sus puestos, desplegarán trayectorias más abiertas y ambiciosas, o serán la "punta de lanza" que abra la llegada de nuevas políticas. Hemos podido conocer cómo la entrada de mujeres en las "concejalías blandas" de algunos de estos municipios precedía al acceso a mayores cuotas de poder, porque la presencia en la política se había hecho acostumbrada y familiar. Concejalas y alcaldesas nos han manifestado la sensación de haber ido abriendo caminos a las mujeres que venían detrás de ellas, dándoles un terreno abonado para 
su desenvolvimiento. En los pequeños municipios, su mayor porcentaje se enfrenta a obstáculos valorativos y funcionales, pero permite ver de forma directa los efectos de su gestión, y otorga una imagen de normalidad. Muchas de nuestras entrevistadas establecían una equiparación automática -tal vez engañosamentre triunfalista- entre el modo en que aumenta el porcentaje de mujeres en la política y el progreso de la sociedad en cuestiones de igualdad de género.

Posiblemente, sólo la normalización de su presencia, todavía excepcional en los máximos rangos de la escena política del medio rural, y la articulación en un nivel colectivo de estas experiencias en lo político con las de otros frentes abiertos por las mujeres, podrá significar un verdadero empoderamiento femenino, que redundará en una mayor equidad en los procesos de toma de decisiones. Por ello, la política de desarrollo para el medio rural andaluz no puede obviar el aporte dinamizador de estos colectivos de mujeres que desbrozan con su esfuerzo una senda plagada de maleza patriarcalista.

\section{Conclusiones}

Nos hemos acercado al modo en el que las mujeres políticas del medio rural andaluz se sienten "políticas" activas, cómo elaboran y viven su propia identidad y, al ser miembros de grupos más amplios de acción e ideología, de gestión y participación, crean una imagen propia, a través de la cual enfocan sus valoraciones, experiencias y proyectos. Sus conclusiones coinciden básicamente con las presentadas en nuestro anterior artículo sobre las emprendedoras rurales en Andalucía (Cruces y Palenzuela 2006):

- $\quad$ Las características de la estructura social del medio rural andaluz y su modelo dominante de valoraciones y comportamientos orientados por los roles asignados a los géneros configuran un marco problemático de partida para la participación de las mujeres en los procesos de toma de decisiones.

- Dichas constricciones alcanzan un mayor nivel para las mujeres que deciden incorporarse a ámbitos especialmente masculinizados, como en nuestro caso la política, muy conectados con procesos de toma de decisiones públicas de los que las mujeres estuvieron tradicionalmente excluidas.

- El análisis cualitativo de las trayectorias políticas de estas mujeres prueba que, en un contexto de evolución favorable y creciente de participación en la vida pública, no se verifica sin embargo una proporcional modificación de los factores cualitativos que siguen asignándoles un espacio propio, que se puede calificar de "liminar", en las responsabilidades políticas municipales.

- A pesar de ese marco restrictivo, las mujeres políticas del medio rural andaluz están desarrollando estrategias personales y colectivas que les permiten no sólo superar esos obstáculos estructurales, sino contribuir con su acción polí- 
tica a disolverlos. Con ello se configuran como agentes dinamizadores de las acciones de desarrollo rural.

En resumen, las mujeres políticas del medio rural andaluz se incorporan al esfuerzo colectivo para la construcción de un marco social menos polarizado en su estructura social, más diversificado en sus bases económicas, menos jerarquizado en los procesos de toma de decisiones y menos segmentado en los roles adscritos a los géneros. Un medio rural andaluz más dinámico, más democrático y más equitativo en el que, sin embargo, todavía persisten obstáculos difíciles de remover, ideologías inalteradas y, por qué no decirlo, estrategias de consentimiento asumidas por las mismas mujeres que protagonizan sus notables transformaciones.

\section{REFERENCIAS BibLIOGRÁFICAS}

Amorós, C. 1990. "Mujer y participación política." Pp. 197-115 en Participación política de las mujeres, compilado por J. Astelarra. Madrid: CIS.

Arrondo, M. 1987. "El Municipio, plataforma de acción a favor de la igualdad de Derechos." Revista Autonomía Local, Hoja Informativa n 1: "Mujer", pp. 4-5. Subcomisión Mujer de la FEMP, Octubre.

Astelarra, J. 1986. Las mujeres podemos: otra visión. Barcelona: Icaria.

Astelarra, J. comp. 1990. Participación política de las mujeres. Madrid: CIS.

Barberá Heredia, E. 2000. "Invisibilidad de las mujeres y representaciones de poder." Pp. 43-59, en Las mujeres del año 2000: hechos y aspiraciones. Madrid: Instituto de la Mujer, Ministerio de Trabajo y Asuntos Sociales.

Bericat, E. y M. Camarero. 1994. Trabajadoras y Trabajos en la Andalucía Rural. Situación socio-laboral de la mujer rural en Andalucía. Sevilla: Instituto Andaluz de la Mujer, Serie Estudios 3.

Breton Solo De Zaldívar, V. 2005. "Los paradigmas de la 'nueva' ruralidad a debate: El proyecto de desarrollo de los pueblos indígenas y negros del Ecuador." Revista Europea de Estudios Latiniamericanos y del Caribe 78:30.

Chayanov, A. [1925] 1974. La organización de la unidad doméstica campesina. Buenos Aires: Nueva Visión.

Camarero, L. et al. 2005. Emprendedoras rurales: de trabajadoras invisibles a sujetos pendientes. Valencia: Centro Francisco Tomás y Valiente-UNED.

Campos, A. y L. Méndez. 1993. "Teoría feminista: identidad, género y política. El estado de la cuestión." XI Cursos de Verano en San Sebastián, Universidad del País Vasco, Bilbao.

Comaille, C. 1999. Les stratégies des femmes. París: La Découverte. 
Cruces, C. y P. Palenzuela. 2006. "Emprendedoras rurales en Andalucía. Posibilidades y límites de sus estrategias." Revista de Estudios Agrosociales y Pesqueros 211:239-305.

Cruz Souza, F. 2006. "Género, psicología y desarrollo rural: la construcción de nuevas identidades." Madrid: Ministerio de Agricultura, Pesca y Alimentación, Serie Estudios 163.

Díaz Méndez, C. 1997. Estrategias familiares y juventud rural. Madrid: Ministerio de Agricultura. Serie Estudios 134.

Díaz Méndez, C. 2005. "Aproximaciones al arraigo y al desarraigo femenino en el medio rural: mujeres jóvenes en busca de una nueva identidad rural." Papers 75:63-84.

Federación Española De Municipios y Provincias (FEMP). 2007. Estudio del impacto de la Ley Orgánica 3/2007 para la igualdad efectiva de mujeres y hombres en la representación de las mujeres en el ámbito de la política local. Madrid: FEMP.

Garrido, F. y E. Moyano. 2002. "Capital social y desarrollo en zonas rurales." Revista Internacional de Sociología 33:67-96.

Lagarde, M. 1999. Claves feministas para el poderío y la autonomía de las mujeres. Sevilla: Instituto Andaluz de la Mujer.

Lagarde, M. 2000. Claves feministas para la autoestima de las mujeres. Madrid: Ed. horas y HORAS.

Massolo, A. 2006. Participación política de las mujeres en el ámbito local en América Latina. Santo Domingo: INSTRAW.

Moyano, E. 2005. "Nuevas orientaciones de la política europea de desarrollo rural." Pp. 75-88 en XII Informe Socioeconómico de la Agricultura familiar en España. Fundación de Estudios Rurales. Madrid.

Palenzuela, P., C. Cruces y M. Jordi. 2002. Mujeres empresarias y mujeres politicas en el medio rural andaluz. Sevilla: Junta de Andalucía-Universidad de Sevilla.

Palerm, A. 1980. "Antropólogos y campesinos: los límites del capitalismo." Pp. 255-292, en A. Palerm; Antropología y marxismo. México: Nueva Imagen-CISINAH.

Porto, F. "Más alcaldesas en las ciudades medias.", Pp. 21-22, en Carta Local 63. Revista de la Federación Española de Municipios y Provincias.

Porto Vázquez, F. y R. Sampedro Gallego. 1991. Los nuevos representantes locales. Madrid: Ed. FEMP.

Prados Velasco, M. J. 2000. La situación socioeconómica de las mujeres rurales en España. Sevilla: Consejería de Agricultura y Pesca, Junta de Andalucía.

Redfield, R. 1973. La pequeña comunidad: sociedad y cultura campesinas. Buenos Aires: Edición 3.

Rogers, E. L. y M. Svenning. 1973. La modernización de los campesinos. México: Fondo de Cultura Económica. 
Sampredo, R. y L. Camarero. 2007. "Mujeres empresarias en la España rural. El sujeto pendiente de desarrollo." Revista Internacional de Sociología 48:121-146.

Shanin, T. 1972. Campesinos y sociedades campesinas. México: FCE.

Sevilla Guzmán, E. 1979. La evolución del campesinado en España. Barcelona: Península.

Uriarte, E. y A. Elizondo. 1996. Mujeres en política. Barcelona: Ariel.

VVAA. 1998. Más mujeres en los poderes locales. Madrid: Fundación Dolores Ubárruri.

Valcárcel, A. 1997. La política de las mujeres. Madrid: Cátedra.

Valcárcel, A. 2001. "La presencia de las mujeres en la toma de decisiones relevantes: los retos del futuro." Pp. en Las mujeres en el año 2000: hechos y aspiraciones. Madrid: Ministerio de Trabajo y Asuntos Sociales, Instituto de la Mujer.

Vera, A. y Rivera, J. 1999. Contribución invisible de las mujeres a la economía. El caso específico del mundo rural. Madrid: Ministerio de Trabajo y Asuntos Sociales, Instituto de la Mujer.

Wolf. E. 1982. Los campesinos. Barcelona: Nueva Colección Labor.

PABLO PALENZUELA CHAMORRO es Catedrático de Universidad en el Departamento de Antropología Social de la Universidad de Sevilla. Sus investigaciones y publicaciones están concentradas en América Latina y Andalucía y en temáticas como las culturas del trabajo, las estrategias económicas domésticas, el medio rural y el desarrollo con identidad.

CRISTINA CRUCES ROLDÁN es Profesora Titular de Universidad en el Departamento de Antropología Social de la Universidad de Sevilla. Sus investigaciones se han centrado en el estudio del sector agrario andaluz y la dimensión de género en diversos ámbitos socio-profesionales, en relación con los procesos de innovación y desarrollo.

RECIBIDO: 03/05/2009

ACEPTADO: 26/10/2009

Publicado on-line: 11/04/2011 